\title{
Consuming e: Ecstasy use and contemporary social life
}

Anna Olsen

Contemporary Drug Problems; Spring 2009; 36, 1/2; Research Library pg. 175

\section{Consuming e: Ecstasy use and contemporary social life}

\author{
BY ANNA OLSEN
}

\begin{abstract}
Research and popular commentary on Ecstasy often frames users as rebellious youth reacting against mainstream society via hedonistic rave parties and reckless intoxication. Critical consideration of the complex social and economic foundations of Ecstasy use is lacking in much of this youth-based research. Growing evidence, for example, suggests that a wide range of people take Ecstasy in a variety of contexts. Through the lens of anthro-economic approaches to consumption this article suggests that although Ecstasy is an illicit drug popular among youth, the symbolic meanings surrounding its use are also connected to the every-day. Accounts of 12 Ecstasy users from Canberra, Australia show how their experiences of Ecstasy, and the value the drug gives to their social relations, are firmly situated within the aspirations and confines of late capitalist consumer society. Participants' narratives were associated with ideologies about vitality, leisure and the importance of being social and energetic without impinging on one's other social responsibilities. Their patterns of Ecstasy consumption were not only connected to subcultural tastes and desires but changing values of leisure and consumption in wider contemporary life.
\end{abstract}

KEY WORDS: Ecstasy, culture, consumption, commodity, leisure

AUTHOR'S NOTE: I acknowledge the guidance of Margot Lyon and Ian Keen who supervised this project. Thanks to Cathy Banwell, Phyll Dance, Daniel Woodman and especially Richard Woolley for their assistance and support in the development of this article. Finally, I express my gratitude to the participants for their time and generosity.

(1) 2009 by Federal Legal Publications. Inc. 
Traditionally in research, as well as media accounts and popular literature on Ecstasy (MDMA; 3,4-methylenedioxymethamphetamine), Ecstasy users have held a fascination as a young "counterculture" linked to the electronic dance music genre. They have been described as a "youth culture" displaying either hedonistic pleasure seeking or rebellion against the mainstream through shared rituals. Those who take Ecstasy at rave parties are commonly said to embody a "hedonistic display of tribal youth culture" (Lyttle \& Montagne, 1992, p. 1160). Here, the complexity of 'Ecstasy culture' can be lost as a result of a relative inattention to meanings or purposes other than the desire to be "spaced out" (Thornton, 1995, p. 133).

Alternatively, Ecstasy users are commonly portrayed as a "social movement attracting increasing numbers of disaffected youth" (Grob, 2000, p. 550). This "shadowy subculture of youth" is theorized to be reacting against the "modern materialism of the 'me' generation," embracing "a party etiquette of peace, love, unity and respect, which is captured in the rave logo 'PLUR'" (Weir, 2000, p. 1843). In a radical search for community (Luckman, 2003) or rebelling against social norms (Jordan, 1995), this interpretation of a "tribal youth culture" relies heavily on concepts of hedonism as revolutionary. Social phenomena involving youth and "new" cultural tastes hold an allure for many as a "metaphor for social change" (Rowe, 1995, p. 4). Depictions of youth are often romanticized and disengaged from the social processes from which they emerge. Examined in contrast to "conventional society," labeled social types-such as punks or ravers or drug users-are often created against the "chimera of a negative mainstream" (Thornton, 1995, p. 93). These cultural studies can occur with little consideration of the effects of wider symbolic, historical, political, economic and social phenomena (Moore, 2004; Thornton, 1995).

Although the consideration of wider social factors in drug research engages the "more difficult study of cultural change 
and the shifting symbolic value of drug use" (Duff, 2005, p. 163 ), there is a continuing need for researchers to move beyond the limitations of young rave-goers to address other contexts and functions in the life of Ecstasy (Agar \& Reisinger, 2004; Williams Boeri, Sterk, \& Elfison, 2004).

\section{Contextual patterns of Ecstasy consumption: Beyond the rave}

The Ecstasy phenomenon in Australian and elsewhere is no longer (and perhaps never was) defined solely by youth who attend rave parties (Hansen, Maycock, \& Lower, 2001; Williams Boeri et al., 2004). As Beck and Rosenbaum's (1994) early US study showed, Ecstasy users are not a homogeneous group nor restricted to a youth culture. They are college students, gays, new-agers, young professionals and rock music devotees.

Research across Australia, the US and Britain reveals that use of all illegal substances is expanding, and Ecstasy is firmly established in this pattern (Boys, Marsden, \& Strang, 2001; Duff, 2005; Forsyth, 1996; Hansen et al., 2001; Moore, 1992, 1993; Parker \& Measham, 1994; Pedersen \& Skrondal, 1999; Williams Boeri et al., 2004). In the years prior to this study, for example, the proportion of Australians aged 14 years and over who used Ecstasy/designer drugs at least once in their lifetime was estimated at 5\% (Australian Institute of Health and Welfare, 2000). The majority of self-reported Ecstasy users were aged between 20-29 years of age and a significant number of users were aged 30 years and above.

Reflecting complex local and global politico-economic changes, the growth in Ecstasy use can been attributed to both the increased availability of the drug and the increased use of all mind-altering substances (Agar \& Reisinger, 2003, 2004). As a result of these patterns, many social researchers now suggest that illicit substances have become a relatively 
normal feature of life for increasing numbers of individuals (Duff, 2005; Parker, Aldridge, \& Measham, 1998; Parker, Williams, \& Aldridge, 2002; South, 2004). Although many deterrents to illicit drug use still exist (Shiner \& Newburn, 1999), the range of people who take drugs and the situations in which illicit drug use is accepted has widened. These changes have created space for a conceptual shift in social discourses around recreational drug use (Henderson, 1997) and raise questions about the role of drug use in society beyond youthful trends.

\section{The social life of things}

As illicit drug use is moderated by social trends and taboos it is closely tied to day-to-day contexts. Like other consumables, drugs are exchanged and experienced between actors, objectify meanings and hold political value (Appadurai, 1986; Douglas \& Isherwood, 1981; Reynolds Whyte, van der Geest, \& Hardon, 2002). Social processes give objects their meanings and significances and patterns of consumption reflect and recreate the structures of social life. Commodities and their consumption are inextricably tied to the material, social and symbolic nature of society and cannot be explained or experienced outside of the particular social parameters in which they are exchanged.

From this theoretical viewpoint, things are symbolic not only because they are given meaning by humans but because they give meaning to human contexts (Appadurai, 1986). Value is embodied in commodities that are exchanged and consumed and thus "we have to follow the things themselves, for their meanings are inscribed in their forms, their uses, their trajectories" in order to understand the desire and demand for an object in society (Appadurai, 1986, p. 5).

While much has been written about the chemical or physiological trajectory of Ecstasy once it is consumed in the body 
less has been said about the relationships Ecstasy has with, and traces between, people. Expanding on the associations that have been considered within the contexts of youth fashion and rave parties this article applies a wider context from which to consider the meanings of Ecstasy in society. Focusing on the material nature of Ecstasy I draw attention back to the forms or functions of Ecstasy consumption in order consider the broader politics, patterns and ideologies that surround its circulation. Using the accounts of 12 interconnected Ecstasy users about why they use Ecstasy, I interpret the value of Ecstasy in their lives and consider how these values elucidate dominant symbolic and political patterns of contemporary life. Instead of asking how Ecstasy use is symbolically distinct from other consumable things, or other processes of consumption, I examine how Ecstasy use can be incorporated into an understanding of the commodity potential of all things.

\section{Method and sample}

In 2001 I interviewed 12 Ecstasy users from Canberra, Australia. Half were known to me as performers, organizers or regular attendees in the local music scene (including the genres of dance, metal and rock music). The remaining participants were recruited via snowballing. Consequently, the sample represents a loose social network of people who use Ecstasy, although they did not all know one another, take the drug together, or use the drug at the same events. Their social connection is largely based on their shared geographical location and their common consumption practices involving recreational Ecstasy use.

Most participants were aged between 18 and 30 years old and were university students and/or in paid employment. The sample included one middle-aged (approximately 40 years old) user of Ecstasy. As other research suggests, consumption of Ecstasy was not confined to raves but included clubs, bars, house parties and music concerts (Hansen et al., 2001; 
Williams Boeri et al., 2004). Most participants' use of the drug was restricted to the occasional weekend, special occasions such as New Years Eve, or large music events. All participants discussed their Ecstasy use as recreational or occasional, although one person disclosed a period of polyillicit drug use that he considered problematic and which had led him to reduce use.

This network of Ecstasy consumers was slightly older than sample cohorts used in many other studies of Ecstasy users and they were recruited outside of raves (a typical recruitment context). Nevertheless, they were, in many ways, also representative of the 'typical' participant in Ecstasy research. They were predominantly middle class, Anglo and young adults; only one participant was middle aged. All were engaged in employment and/or university; it has been found that Australians living in areas with high socioeconomic status are twice as likely to report using Ecstasy/designer drugs as persons in the bottom quintile of the socioeconomic scale (Australian Institute of Health and Welfare, 2000). Thus, while this sample is not representative of all Australian Ecstasy users it is potentially typical of middle class, Anglo young adults who depict themselves as "normal people with full rounded lives, who also happen to use Ecstasy" (Solowij \& Lee, 1991, p. 10).

Using semistructured interview techniques and open-ended questions I asked participants why they (and others) used Ecstasy; how, where, when and with whom they used it; the use of other drugs; the "scene" around Ecstasy; and about its national and international popularity. Notes were taken during the interviews including verbatim quotes and abbreviated comments on our discussion. I qualitatively analyzed the verbatim quotes using thematic coding. Thematic coding analysis involves examining participants' accounts for shared experiences and meanings. Described as themes, these shared meanings were then further interpreted for wider social, political and economic relevance. The key themes that emerged 
from participants' accounts form the basis of this article. All participant descriptions below employ pseudonyms.

\section{$E$ is for energy}

The most dominant theme repeated across all interviews was energy. Participants' described desiring Ecstasy because of its vitalizing effects. All participants saw the drug as a substance that could enhance a social event through its ability to provide enhanced energy.

It heightens everything, makes me feel alert and aware . . and feel like you are really alive. .. I don't take Ecstasy to get off the planet but to boost energy. ... (Josh, early-twenties university student)

The enjoyment of Ecstasy for these users was not so much to "get wasted" or to rebel but to enhance vitality within milieus of sociality. Ecstasy was seen to be a relatively safe substance that could help provide the complementary qualities of increased energy and reduced inhibitions in a social environment.

It makes your normal clubbing adventure fun and extremely sociable.

(Andrew, early-twenties, employed)

Findings from similar research in Australia and the UK also suggests that staying up long hours to socialize is the key purpose of Ecstasy for the majority of users (Cohen, 1995; Lenton, Boys, \& Norcross, 1997; Solowij \& Lee, 1991; Williams \& Parker, 2001). Participants in these studies associate Ecstasy with clubs, parties, raves and other social events where it is desirable to stay alert and active for as long as possible.

Placed in the context of contemporary social life, the popularity of a drug that can increase your vitality is highly consistent. Use of substances to improve one's energy is not a new practice nor is it uncommon. Caffeine has been used as a stimulant for hundreds of years, impacting on how societies view work, sobriety and control of the body (Schivelbusch, 1992). Today, a quick look around a local Australian shop- 
ping centre reveals a huge range of energy-boosting drinks, herbal pick-me-ups like guarana, and foods boasting ironman-like vigor with consumption. Marketing of legal commodities commonly uses descriptions and imagery in which the "docile body" is transgressed via consumption of the product (Fitzgerald, 2002, p. 225).

Numerous goods offer altered bodily states (health, energy, frivolity, etc), both chemically and by association. Both licit and illicit substances are used to "kick-start our emotions on Friday evening" (Mugford, 1991, p. 254). Indeed, New Zealand has recently experienced a boom in legal party drugs containing amphetamine-like substances advertised to provide enhanced stamina and libido in a pill (New Zealand Drug Foundation, 2009).

Despite its social categorization as an illicit substance, Ecstasy is still subject to the dynamics of consumption culture (Fitzgerald, 2002) and the long-established patterns of demand that act as constraints in commodity exchange and consumption (Appadurai, 1986). Previous socioeconomic work on Ecstasy suggests that the variety of designs and names for different batches of Ecstasy enables consumers to select a tablet on the basis of both its chemical composition and its commercial identity (Fitzgerald, 2002; Forsyth, 1995).

On a global scale, Ecstasy is not only impacted on by other commodities but is associated with various meanings of fun, energy and pleasure in consumer culture. Mainstream consumable products from energy drinks to clothing and vitamins are regularly associated with Ecstasy and other party drugs. The past decade has seen a number of manufacturers employ the letter e on product labels or use circular pill-like logos to advertise the vitality of their merchandise. This, writes Fitzgerald (2002), has led to commodities such as legal beverages becoming associated with illegal consumption experiences, while illicit activities become associated with legal advertising and consumption. 


\section{Enhancement}

Related to energy (and the desire for it), many participants described other enhancing powers of Ecstasy. The augmentation of human performance and its link to enjoyment and vitality has already been exemplified and endorsed by the likes of Timothy Leary and Carlos Castaneda. In today's world, however, psychoactive substances, or "chemical prosthetics" (Fitzgerald, 2005), are now arguably more available and widely used than ever before. Technologies of enhancement ranging from surgery to "smart drugs" are used by humans to boost various aspects of themselves (Elliott, 1998).

In my interview with Paul (late-teens, university student), he described Ecstasy as a "futuristic drug" because it provides, in an easily consumable form, effects that are often desired in social situations-energy, openness and calmness. He felt that his generation had grown-up taking pills as the quick-fix answer to physical sickness, and that this pattern may now be extending to other areas of life, in this case, sociality and pleasure. Indeed, among other commodity trends, Ecstasy's surge in popularity coincides with an increase in the prescription of pharmaceutical medications for depression, anxiety, hyperactivity, and a range of other "disorders." In Listening to Prozac, Kramer (1993) describes how "cosmetic psychopharmacology," or psychopharmaceuticals, offer individuals the enhanced ability to perform in more socially desirable ways.

The growing appeal of cosmetic psychopharmacology is apparent among US college students whose recreational use of prescribed stimulants (such as methylphenidate) has increased in recent years (Low \& Gendaszek, 2002; McCabe, Knight, Teter, \& Wechsler, 2005). Students report taking stimulants for academic reasons (primarily to stay alert while studying) as well as for pleasure.

When discussing reasons for taking Ecstasy, users in this study felt that the drug could change (generally positively) the experience of being in a particular social space. 
It is not that you have a bad night if you don't do e, just a better night if you do.

(Gus, early-twenties, university student)

The power of Ecstasy went beyond improving one's stamina during a social event to include enhancement of the self. Chris (early twenties, Technical College student) experienced Ecstasy use as a tool for himself and others to expose concealed parts of the self. He believed that Ecstasy had significantly impacted on his personal concept of self:

People can access parts of themselves . . to forget for a moment the different rules they place on themselves. . . You had that chance to see yourself, the inner parts that are generally governed by rules.

Access to a different or improved self through Ecstasy was not only transitory (during one social event or special occasion). For some users Ecstasy offered a transformation of the mind and body with lasting impact. Russell (early-twenties university student) reported that he originally believed Ecstasy enabled him access to a new self, perhaps a more sociable self, who is fun, happy and outgoing:

When I first starting taking e I just took whatever pill I could get. I thought that it would change me, affect my outlook on things... . you see this pill and there is a different you in there. It represents fun, happiness and excitement.

"Technologies of the self," writes Foucault, offer transformation into "a certain state of happiness, purity, wisdom, perfection, or immortality" and allow individuals to carry out operations "on their own bodies and souls, thoughts, conduct, and way of being" (Foucault, 1988, p. 18). The individual power expressed in these transformations, however, is socially constructed. Customs, norms and practices are designed to determine "how the individual is supposed to constitute himself as a moral subject of his own action" (Foucault, 1983, p. 238). 


\section{Ideologies of work and leisure}

Among individuals I interviewed, Ecstasy use was moderated and this was closely related to moralistic norms about illicit drugs and leisure time. Participants' accounts of when and where they used Ecstasy included moral narratives about when and where it was appropriate to take the drug. They presented Ecstasy as a pleasurable or fun tool used by people in their leisure time, but that is not suitable for consumption outside of venues and times employed for entertainment and socializing.

I think that you would be crazy to take it anywhere else where you are not letting off energy, . . . you need a particularly high energy environment.

(Josh, early-twenties, university student)

The politics of consumption "account for the vagaries of demand" (Appadurai, 1986, p. 57). According to Hage and Powers (1992, p. 86), leisure only became an "important way of expressing and nourishing the self" in our postindustrial society. As we separate work and leisure, we have become bound by the social structures of the "Protestant Work Ethic" (Dance \& Mugford, 1992; Mugford \& Cohen, 1989; Weber, 1997). Production, duty, effort and wage earning is not, in general, time of one's own. Conversely, leisure is associated with pleasure, consumption and free time.

The relationship between leisure and recreational drug use has been noted by proponents of the normalization thesis, in which it is suggested that recreational illicit drug use has become an acceptable part of life for younger generations (Parker et al., 1998; Parker et al., 2002). The growing tolerance of "sensible recreational drug use" outside of school and work (Parker et al., 1998, p. 947) suggests a growing number of "well-adjusted and successful goal-oriented, nonrisk taking young persons, who see drug taking as part of their repertoire of life" (Parker, 1997, p. 25). However, this acceptance of drugs has not disengaged users from social values separating work from leisure (Henderson, 1997). 
Participants interviewed for this study also expressed a generally positive attitude toward recreational drug use in the confines of one's leisure time. Construction of the "moral subject" (Foucault, 1983, p. 238) in these accounts drew on dual notions of work and play, and participants discussed how Ecstasy could be used without disrupting other social responsibilities. This was contrasted with the use (or abuse) of other more "hardcore" illicit substances.

Anything more than e and you are getting more hardcore, because it doesn't seem to be addictive. . . I don't think that it is socially acceptable to be addicted to drugs.

(Josh, early-twenties, university student)

Montagne (1988, pp. 142-143) refers to the negative symbolism of hard drugs in society as "social metaphors" for moral weakness and a lack of self-control. Users of hard drugs, namely heroin, are not regarded as active members of society. They are considered to lack self-control when their drug use becomes an addiction and they can not restrict drug use to leisure-pleasure time. As Harry elucidated: "some drugs seem to undermine the work ethic, whereas with MDMA [Ecstasy] you are going to be a bit sketchy but it is temporary."

Over the past century the process of individualization has led to societal expectations about individual choice (Beck \& Beck-Gernsheim, 2002). Lifestyle preference has become the new way of exercising freedom in the world of the "sovereign consumer" (O'Malley \& Valverde, 2004, p. 38). Social attitudes to choice and the supposed liberalism surrounding it, however, cling tightly to socially directed disciplines of the self (Foucault, 1988). Accessing pleasure, for example, is governed by what Featherstone (1991, p. 59) refers to as "calculated hedonism." Encouragement to consume enjoyment is connected to reward for effort.

Together, these ideologies attributed to Western neoliberalism create a tension between the "the presumptive right to pleasure and a duty to govern risks" (O'Malley \& Valverde, 2004, 
p. 39). The self has become the medium for both liberation and control and illicit drug consumption holds a complex position within this mix. Among the people I interviewed, this flux of meanings was apparent in their descriptions of enjoyment in one's leisure time balanced against moral judgments of uncontrolled drug use. As a result of the powers attributed to Ecstasy, however, use of the drug was able to sit relatively comfortably within their desires and expectations of social life.

\section{Conclusions}

Ecstasy has become a familiar commodity with cult status. A household name and emblem for partying and pleasure, Ecstasy is often depicted as an unusual subcultural fashion. Yet, the marginalization of Ecstasy use as a youth fad can obscure the social designs of its consumption within capitalism and the emergence and durability of cultures of drug-taking.

In this article I have attempted to redirect attention away from the mystification of Ecstasy use as a new youth practice towards its every-day material symbolism, more specifically, to the social act of its consumption. Perceiving the extent to which it is customary to consume illicit drugs in day-to-day life allows for a broader understanding of its use as desirable and accepted (Kane, 2005). Focusing on the forms or functions of Ecstasy consumption among this network of 12 users has enabled me to present relationships between Ecstasy and other "mainstream" contemporary ideologies and practices. I provide evidence for a variety of cultural meanings attached to the drug, including echoes of every-day consumer patterns common to modern life. The parallels I have drawn between participants' views of Ecstasy as both energizing and transforming, and wider patterns in the availability and use of other commodities with similar effects, suggests a social life in which Ecstasy can sit comfortably. In particular, I argue that from the viewpoint of widespread, mass consumption of 
chemical enhancement, Ecstasy use no longer appears exotic in relation to both mainstream society and youth cultures. Our society seeks extra enhancement from many commodities in many environments and the emergence of Ecstasy across the globe is no extraordinary story within this expanded analytical frame.

Agar, M. \& Reisinger, H. S. (2003). Going for the global: The case of Ecstasy. Human Organization, 62(1), 1-11.

Agar. M.. \& Reisinger, H. S. (2004). Ecstasy: Commodity or disease. Journal of Psychoactive Drugs, 36(2), 253-264.

Appadurai, A. (1986). Introduction: Commodities and the politics of value. In A. Appadurai (Ed.), In The social life of things: Commodities in cultural perspective (pp. 3-63). Cambridge: Cambridge University Press.

Australian Institute of Health and Welfare. (2000). 1998 National Drug Strategy Household Survey. Canberra.

Beck, J., \& Rosenbaum. M. (1994). Pursuit of Ecstasy: The MDMA experience. Albany: State University of New York Press.

Beck. U.. \& Beck-Gernsheim. E. (2002). Individualization: Institutionalized individualism and its social and political consequences. London: Sage.

Boys, A., Marsden, J.. \& Strang, J. (2001). Understanding reasons for drug use amongst young people: A functional perspective. Health, Education and Research, I6(4), 457-469.

Cohen, R. S. (1995). Subjective reports on the effects of MDMA ('Ecstasy') experience in humans. Progress in Neuro-Psychopharmacology and Biology Psychiatry, 19.1137-1145.

Dance, P., \& Mugford, S. (1992). The St. Oswald's day celebrations: "Carnival" versus "sobriety" in an Australian drug enthusiast group. The Journal of Drug Issues, 22(3), 591-606.

Douglas, M., \& Isherwood, B. (1981). The world of goods. New York: Basic Books.

Duff. C. (2005). Party drugs and party people: Examining the "normalization" of recreational drug use in Melbourne. Australia. International Journal of Drug Policy, 16, 161-170.

Elliott. C. (1998, Feb. 26). What's wrong with enhancement technologies. Paper presented at the CHIPS Public Lecture, University of Minnesota. 
Featherstone. M. (1991). The body in consumer culture. In B. Turner (Ed.), The body: Social process and cultural theorv. London: Sage.

Fitzgerald, J. (2005). Stimulants. neuroenablement and hope. DrugInfo Newsletter, December.

Fitzgerald, J. L. (2002). A political economy of "Doves." Contemporary Drug Problems, 29, 201-239.

Forsyth. A. J. M. (1995). Ecstasy and illegal drug design: A new concept in drug use. The International Journal of Drug Policy, 6(3). 193-209.

Forsyth, A. J. M. (1996). Places and patterns of drug use in the Scottish dance scene. Addiction, 91(4), 511-521.

Foucault. M. (1983). On the genealogy of ethics: An overview of work in progress. In H. Dreyfus \& P. Rabinow (Eds.), Michel Foucault: Beyond structuralism and hermeneutics. Chicago: University of Chicago Press.

Foucault, M. (1988). Technologies of the self. In L. H. Martin. H. Gutman. \& P. H. Hutton (Eds.), Technologies of the self: A seminar with Michel Foucault. Amherst. MA: University of Massachusetts Press.

Grob, C. S. (2000). Deconstructing Ecstasy: The politics of MDMA research. Addiction Research, 8(6), 549-588.

Hage, J.. \& Powers, C. H. (1992). Post-industrial lives: Roles and relationships in the 21st century. Newbury Park: Sage.

Hansen, D., Maycock, B., \& Lower. T. (2001). "Weddings, parties, anything ...." a qualitative analysis of Ecstasy use in Perth, Western Australia. International Journal of Drug Policy, 12, 181-199.

Henderson. S. (1997). Ecstasy: Case unsolved. London: Harper Collins.

Jordan, T. (1995). Collective bodies: Raving and the politics of Gilles Deleuze and Felix Guattari. Body and Society, 1, 125-144.

Kane, R. (2005). Recreational states: Drugs and the sovereignty of consumption. Edition 7. Culture Machine. 9.

Kramer. P. D. (1993). Listening to Prozac. New York: Penguin.

Lenton, S., Boys, A., \& Norcross. K. (1997). Raves, drugs and experience: Drug use by a sample of people who attended raves in Western Australia. Addiction, 92, 1327-1337.

Low. G. K.. \& Gendaszek, A. E. (2002). Illicit use of psychostimulants among college students: A preliminary study. Psychology, Health \& Medicine, 7(3), 283-287. 
Luckman, S. (2003). Going bush and finding one's "tribe": Raving, escape and the bush doof. Continuum: Journal of Media \& Cultural Studies, $17(3), 315-330$.

Lyttle. T., \& Montagne, M. (1992). Drugs, music and ideology: A social pharmacological interpretation of the acid house movement. The International Journal of the Addictions, 27(10), 1159-1177.

McCabe. S. E., Knight. J. R., Teter, C. J., \& Wechsler, H. (2005). Non-medical use of prescription stimulants among US college students: Prevalence and correlates from a national survey. Addiction, 100(1), 96-106.

Montagne. M. (1988). The metaphorical nature of drugs and drug taking. Social Science and Medicine, 26, 417-424.

Moore. D. (1992). Recreational drug use, with particular reference to amphetamines, Ecstasy and LSD, amongst a social network of young people in Perth, Western Australia. Perth: National Centre for Research into the Prevention of Drug Abuse.

Moore, D. (1993). Speeding. ecking and tripping: Ethnographic notes from a small world of psychostimulant use. In D. Burrows, B. Flaherty, \& M. MacEvoy (Eds.). Illicit Psychostimulant Use in Australia (pp. 7190). Canberra: Australian Government Printing Service.

Moore. D. (2004). Beyond "subculture" in the ethnography of illicit drug use. Contemporary Drug Problems, 31(2), 181-212.

Mugford. S. (1991). Controlled drug use among recreational users: Sociological perspectives. In N. Heather, W. R. Miller \& J. Greeley (Eds.), Self-control and the addictive behaviours. Sydney: Maxwell MacMillan Publishing.

Mugford, S., \& Cohen, P. (1989). Drug use, social relations and commodity consumption: A study of recreational cocaine users in Sydney, Canberra and Melbourne. Canberra: Report to the Research into Drug Abuse Advisory Committee. National Campaign Against Drug Abuse.

New Zealand Drug Foundation. (2009). Party Pills. 2009. from http://www.nzdf.org.nz/party-pills

O'Malley, P.. \& Valverde. M. (2004). Pleasure, freedom and drugs: The uses of "pleasure" in liberal governance of drug and alcohol consumption. Sociology, 38(1). 25-42.

Parker. H. (1997). Adolescent drugs pathways in the 1990s. In J. Braggins (Ed.), Tackling drugs together: One year on. London: Institute for the Study and Treatment of Delinquency.

Parker. H.. Aldridge. J.. \& Measham. F. (1998). Illegal leisure: The normalization of adolescent drug use. London: Routledge. 
Parker. H.. \& Measham, F. (1994). Pick ' $n$ ' mix: Changing patterns of illicit drug use amongst 1990s Adolescents. Drugs, Education, Prevention and Policy, $1(1), 5-13$.

Parker, H., Williams, L., \& Aldridge, J. (2002). The normalization of 'sensible' recreational drug use: Further evidence from the North West England Longitudinal Study. Sociology, 36(4), 941-964.

Pedersen, W., \& Skrondal, A. (1999). Ecstasy and new patterns of drug use: A normal population study. Addiction, 94(11). 1695-1706.

Reynolds Whyte, S., van der Geest, S., \& Hardon, A. (2002). Social lives of medicines. Cambridge: Cambridge University Press.

Rowe. D. (1995). Popular cultures: Rock music, sport and the politics of pleasure. London: Sage Publications.

Schivelbusch, W. (1992). Tastes of paradise: A social history of spices, stimulants, and intoxicants. New York: Pantheon Books.

Shiner, M., \& Newburn. T. (1999). Taking tea with Noel: The place and meaning of drug use in everyday life. In N. South (Ed.), Drugs: Cultures, controls and everyday life. London: Sage.

Solowij. N., \& Lee, N. (1991). Survey of Ecstasy [MDMA] users in Sydney. Sydney: Drug and Alcohol Directorate. New South Wales Health Department.

South, N. (2004). Managing work, hedonism and "the borderline" between legal and illegal markets: Two case studies of recreational heavy drug users. Addiction Research and Theory, 12(6), 525-538.

Thornton, S. (1995). Club cultures: Music, media and subcultural capital. Cambridge: Blackwell.

Weber, M. (1997). The Protestant ethic and the spirit of capitalism. London: Routledge.

Weir, E. (2000). Raves: A review of the culture, the drugs and the prevention of harm. Canadian Medical Association Journal, 162(13), 1843 1848.

Williams Boeri, M.. Sterk. C. E.. \& Elfison, K. W. (2004). Rolling beyond raves: Ecstasy use outside the rave setting. Journal of Drug Issues, $34(4), 831-859$.

Williams, L., \& Parker, H. (2001). Alcohol, cannabis, Ecstasy and cocaine: Drugs of reasoned choice amongst young adult recreational drug users in England. International Journal of Drug Policy, 12, 397 413). 
RONALD A. KNIBBE is a Professor at the Department of Health. Education and Promotion, University of Maastricht, the Netherlands (r.knibbe@gvo.unimaas.nl). His research focuses upon the social backgrounds of substance use. Presently he supervises six projects in the field of tobacco, alcohol and drug use.

SUDIRMAN NASIR has worked in harm reduction associated with drug use and HIV/AIDS with nongovernment agencies in Makassar, Indonesia. He is currently completing a PhD in the School of Population Health, University of Melbourne and is researching the impact of the social context of the lorong on drug use.

HILDIGUNNUR ÓLAFSDÓTTIR is an Independent Scholar at the Reykjavik Academy, Hringbraut 121, 107 Reykjavik, Iceland (hildigunnur @akademia.is). Her research focuses on trends in alcohol consumption and consequences of drinking, public drinking, violence, and alcohol policy. She is at work on the history of The State Alcohol and Tobacco Company of Iceland.

ANNA OLSEN recently completed her PhD in socio-cultural anthropology at the Australian National University, Canberra (National Centre for Epidemiology and Population Health, ANU, Bldg 62, Mills Rd., Canberra, ACT 0200, Australia; anna.olsen@anu.edu.au).Her background is in the anthropology of health and illness and social research on illicit drug use and policy. Research interests include socio-political understandings of illicit drug use and blood borne viruses; women's access to sexual and reproductive health; and HIV/AIDS in China. Anna is currently teaching in China.

JAYADEEP PATRA is a research scientist at the Centre for Addiction and Mental Health (33 Russell Street, Room T-406, Toronto, Ontario M5S 2Sl, Canada Jayadeep_Patra@camh.net). His main research interests center around addiction, drug intervention, public health, alcohol attributable global burden of disease, cost analysis, meta analyses, and latent class analyses.

KIRSIMARJA RAITASALO is a researcher at the Alcohol and Drug Research Group in National Research and Development Centre for Welfare and Health, Helsinki, Finland (Kirsimarja.raitasalo@stakes.fi).Her doctoral thesis is entitled. "Informal Social Control of Drinking: Finland in the Light of International Comparison." 